\title{
OCORRÊNCIA DE ENTEROPARASITAS EM SALAS DE ESPERA E BANHEIROS DE UNIDADES BÁSICAS DE SÁUDE (UBS) NO MUNICÍPIO DE CERES-GO, BRASIL
}

OCCURRENCE OF ENTEROPARASITES IN WAITING ROOMS AND BATHROOMS OF BASIC HEALTH UNITS (BHU) IN THE CITY OF CERES-GO, BRAZIL

\section{Milce Costa (COSTA, M.)}

Doutora em Medicina Tropical - área de concentração: Microbiologia - IPTSP/UFGO.

Docente da FACER - Faculdade Evangélica de Ceres. Ceres - GO, Brasil.

milcebiomol@yahoo.com.br

\section{Ludimila Gonçalves de Lima (LIMA, L.G)}

Acadêmica do Curso de Biomedicina da FACER - Faculdade Evangélica de Ceres-GO: ludmilalima-13@hotmail.com

\section{Hellen Kássia Silva Martins (MARTINS, H.K.S)}

Acadêmica do Curso de Biomedicina da FACER - Faculdade Evangélica de Ceres-GO: hellenyes@hotmail.com

\section{Endereço para correspondência:}

Av. Brasil, S/n, Qd. 13, Morada Verde, Ceres-GO, Brasil. CEP: 76300-000. milcebiomol@yahoo.com.br

\section{RESUMO}

INTRODUÇÃO: As parasitoses intestinais apresentam alta prevalência no mundo todo. Tal situação se deve à precariedade das condições de saneamento básico associadas à falta de higiene pessoal. Locais públicos como as Unidades Básicas de Saúde (UBS), onde existe um grande fluxo de pessoas, facilitam o processo de disseminação e estabelece uma considerável via de contaminação. OBJETIVO: O presente estudo foi realizado no intuito de analisar a presença de enteropasitas nas superfícies e objetos das seis UBS da cidade de Ceres-GO e indiretamente verificar a limpeza das unidades. METODOLOGIA: Trata-se de uma pesquisa de campo analítica. Foram coletadas amostras de todas as seis UBS do município por meio da técnica Graham e as análises foram realizadas através de microscopia óptica. RESULTADOS E DISCUSSÃO: Foram analisadas um total de 210 lâminas. Destas, 9 (4,3\%) lâminas 
mostraram-se positivas para ovos de enteroparasitas. Das amostras positivas, verificou-se que 7 (3,3\%) lâminas eram referentes a ovos de Ascaris lumbricoides e 2 (1\%) lâminas pertenciam a ovos de Enterobius vermicularis. Nas 201 (95,7\%) lâminas restantes, os resultados foram negativos. Verificou-se a presença de ovos de A. lumbricoides nas UBS C, D, E e F perfazendo um total de $n=7$ lâminas positivas. Destas, $n=3(42,8 \%)$ eram provenientes de maçanetas internas dos banheiros, sendo este o objeto com maior percentual de contaminação. A pesquisa evidenciou ainda a presença de ovos de E. vermicularis nas UBS A e B $(\mathrm{n}=2)$ sugerindo que os usuários apresentem hábitos higiênicos inadequados. CONCLUSÃO: Podese observar que os índices de contaminação parasitária em todas as UBS foram relativamente baixos, sugerindo que a limpeza é adequada.

Palavras-chave: Helmintos. Unidades Básicas de Saúde. Graham.

\section{ABSTRACT}

INTRODUCTION: Intestinal parasitoses present high prevalence worldwide. This situation is due to the precarious conditions of basic sanitation associated with lack of personal hygiene. Public places such as the Basic Health Units (BHU), where there is a large flow of people, facilitate the process of dissemination and establish a considerable path of contamination. OBJECTIVE: The present study was carried out to analyze the presence of enteropasites on the surfaces and objects of the six BHU in the city of Ceres-GO and indirectly to verify the cleanliness of the units. METHODOLOGY: This is an analytical field research. Samples were collected from all six BHU of the municipality using the Graham technique and the analyzes were performed using light microscopy. RESULTS AND DISCUSSION: A total of 210 slides were analyzed. Of these, 9 (4.3\%) slides were positive for enteroparasite eggs. From the positive samples, it was verified that 7 (3.3\%) slides were referring to Ascaris lumbricoides eggs and $2(1 \%)$ slides belonged to Enterobius vermicularis eggs. In the remaining $201(95.7 \%)$ slides, the results were negative. The presence of $A$. lumbricoides eggs in BHU C, D, E and F was verified for a total of $\mathrm{n}=7$ positive slides. Of these, $n=3(42.8 \%)$ came from internal door handles of the bathrooms, being the object with the highest percentage of contamination. The research also evidenced the presence of $E$. vermicularis eggs in the UBS A and B $(n=2)$ suggesting that the users present inadequate 
hygienic habits. CONCLUSION: It can be observed that the rates of parasitic contamination in all BHU were relatively low, suggesting that cleaning is adequate.

Keywords: Helminths. Basic Health Units. Graham.

\section{INTRODUÇÃO}

As infecções intestinais ocasionadas por protozoários e helmintos apresentam alta prevalência no mundo todo, principalmente em países subdesenvolvidos ou em desenvolvimento onde se encontram populações em precárias condições de higiene e saneamento básico. Segundo a Organização Mundial de Saúde (OMS), 3,5 bilhões de indivíduos são afetados por parasitas intestinais. No Brasil, as helmintíases intestinais apresentam uma vasta distribuição geográfica em virtude das condições inerentes ao clima, disponibilidade de vetores mecânicos, ausência de políticas públicas eficazes e inexistência de medidas de educação em saúde à população carente (NEVES et al, 2011; MELO et al., 2015; MORALES, 2016).

A ocorrência das altas taxas de helmintíases no Brasil está ligada, sobretudo, às formas de transmissão e disseminação dos ovos, o que explica as elevadas taxas de surtos epidêmicos. No que diz respeito à disseminação dos ovos no ambiente, existem estudos que evidenciam alguns fômites como: moedas, cédulas de dinheiro e chupetas de crianças. Em locais como ônibus de transporte coletivo e sanitários públicos, os elementos manuseados por um grande número de pessoas como: corrimão, roleta, assentos, descarga (botão ou puxador), trinco das portas, maçanetas (interna e externa) e registro de torneira estão altamente envolvidos no processo de disseminação. Outros elementos como água; material subungueal, vetores mecânicos e hortaliças também devem ser considerados na disseminação dos ovos (COELHO et al., 1999; COELHO et al., 2001; REQUENA et al., 2007; BORGES et al., 2009; MURTA e MASSARA, 2009; SILVA et al., 2011).

No caso de ambientes públicos como as Unidades Básicas de Saúde (UBS), onde o fluxo de indivíduos que circula em busca de diagnóstico e tratamento é grande, pode-se considerar que o espaço físico compartilhado (bancada de atendimento, assentos, maçanetas de sanitários) facilitam enormemente o processo de disseminação de ovos, estabelecendo-se como via de contaminação, principalmente considerando-se a resistência dos ovos no ambiente (SILVA et al., 2013). 
Dessa forma, o estudo teve por objetivo verificar a presença de ovos de enteroparasitas em objetos das salas de espera e em banheiros nas seis UBS da cidade de Ceres-GO.

\section{METODOLOGIA}

\section{Solicitação de Coleta}

Para realização da coleta do material foram apresentados ofícios enviados pela Faculdade Evangélica de Ceres à Secretaria de Saúde do município de Ceres-GO, bem como para cada UBS analisada. Uma vez autorizada a coleta, houve permissão para o acesso das pesquisadoras nas UBS conforme agendamento estabelecido neste estudo.

\section{Local da coleta}

Trata-se de uma pesquisa de campo analítica. A coleta das amostras foi realizada nas seis UBS da cidade de Ceres-GO entre os meses de agosto e setembro de 2018, totalizando cinco coletas em cada UBS, sempre após o expediente e antes da limpeza. O material coletado nas seis UBS incluídas no estudo (A, B, C, D, E, F), foi proveniente de objetos localizados onde ocorre maior circulação de pessoas, como bancada de atendimento, cadeiras da sala de espera e maçanetas interna e externa dos banheiros masculino e feminino.

Na Tabela 1 podemos verificar a quantidade de objetos analisados por coleta em cada uma das seis UBS. Foram examinados 42 objetos por coleta, sendo 7 em cada Unidade (A, B, C, D, E, F). 
Tabela 1. Relação de objetos analisados por coleta em cada UBS no município de Ceres-GO

\begin{tabular}{llllllll}
\hline \multirow{2}{*}{ Objetos } & \multicolumn{6}{c}{ Unidade Básica de Saúde (UBS) } & \multirow{2}{*}{$\begin{array}{c}\text { Objetos } \\
\text { examinados por } \\
\text { coleta }\end{array}$} \\
\hline Assento de cadeiras & A & B & C & D & E & F & 12 \\
\hline Bancada de atendimento & 1 & 1 & 1 & 1 & 1 & 1 & 6 \\
\hline $\begin{array}{l}\text { Maçanetas internas } \\
\text { Banheiro masculino e } \\
\text { feminino }\end{array}$ & 2 & 2 & 2 & 2 & 2 & 2 & 12 \\
\hline $\begin{array}{l}\text { Maçanetas externas } \\
\text { Banheiro masculino e } \\
\text { feminino }\end{array}$ & 2 & 2 & 2 & 2 & 2 & 2 & 12 \\
\hline Total & 7 & 7 & 7 & 7 & 7 & 7 & 42 \\
\hline
\end{tabular}

\section{Técnica empregada para coleta e observação das amostras}

Para realização das coletas, foi utilizada a técnica Graham (1941), conhecida também como método da fita adesiva ou fita gomada, com modificação para superfície de objetos. Esta técnica também é utilizada para identificação de ovos de outras espécies de helmintos intestinais (MURTA e MASSARA, 2009). A técnica consistiu na utilização de uma fita adesiva transparente de seis centímetros de comprimento, sobreposta por até seis vezes sobre cada local da superfície pesquisada. Posteriormente, a fita foi fixada em uma lâmina de vidro com uma codificação pré-determinada que identificasse a UBS e o objeto, de modo que quem examinou o material, não tivesse acesso à designação deste código. As análises foram realizadas utilizando microscópio óptico no aumento de 400X no Laboratório de Microscopia da Faculdade Evangélica de Ceres-GO.

\section{RESULTADOS E DISCUSSÃO}

Uma vez realizadas as cinco coletas por UBS, esquematizadas na metodologia deste estudo, foram analisadas um total de $n=210$ lâminas. Os objetos analisados foram distribuídos da seguinte forma: 60 assentos de cadeira (12 por coleta), 30 bancadas de atendimento ( 6 por coleta), 60 maçanetas internas de banheiro masculino e banheiro feminino (12 por coleta), 60 maçanetas externas de banheiro masculino e banheiro feminino (12 por coleta).

Das 210 lâminas examinadas, n=9 (4,3\%) lâminas mostraram-se positivas para ovos de enteroparasitas. Das amostras positivas, verificou-se que $n=7$ (3,3\%) lâminas eram referentes 
a ovos de A. lumbricoides e n=2 (1\%) lâminas pertenciam a ovos de E. vermicularis. Nas $\mathrm{n}=201(95,7 \%)$ lâminas restantes, os resultados foram negativos (Figura 1). O baixo índice de contaminação por parasitas $(4,3 \%)$ verificado nas seis UBS pesquisadas neste estudo, indica possivelmente que a higienização do local bem como a desinfecção dos objetos e superfícies esteja sendo realizadas de forma apropriada e com regularidade. Mesmo que ocorra grande circulação de pessoas nestes ambientes, o controle da limpeza está atendendo à proposta de manter o ambiente funcionando com mínima contaminação de parasitas circulantes (SCHOLTE et al., 2015).

Figura 1. Presença de enteroparasitas em objetos das salas de espera e banheiros das UBS na cidade de Ceres-GO.

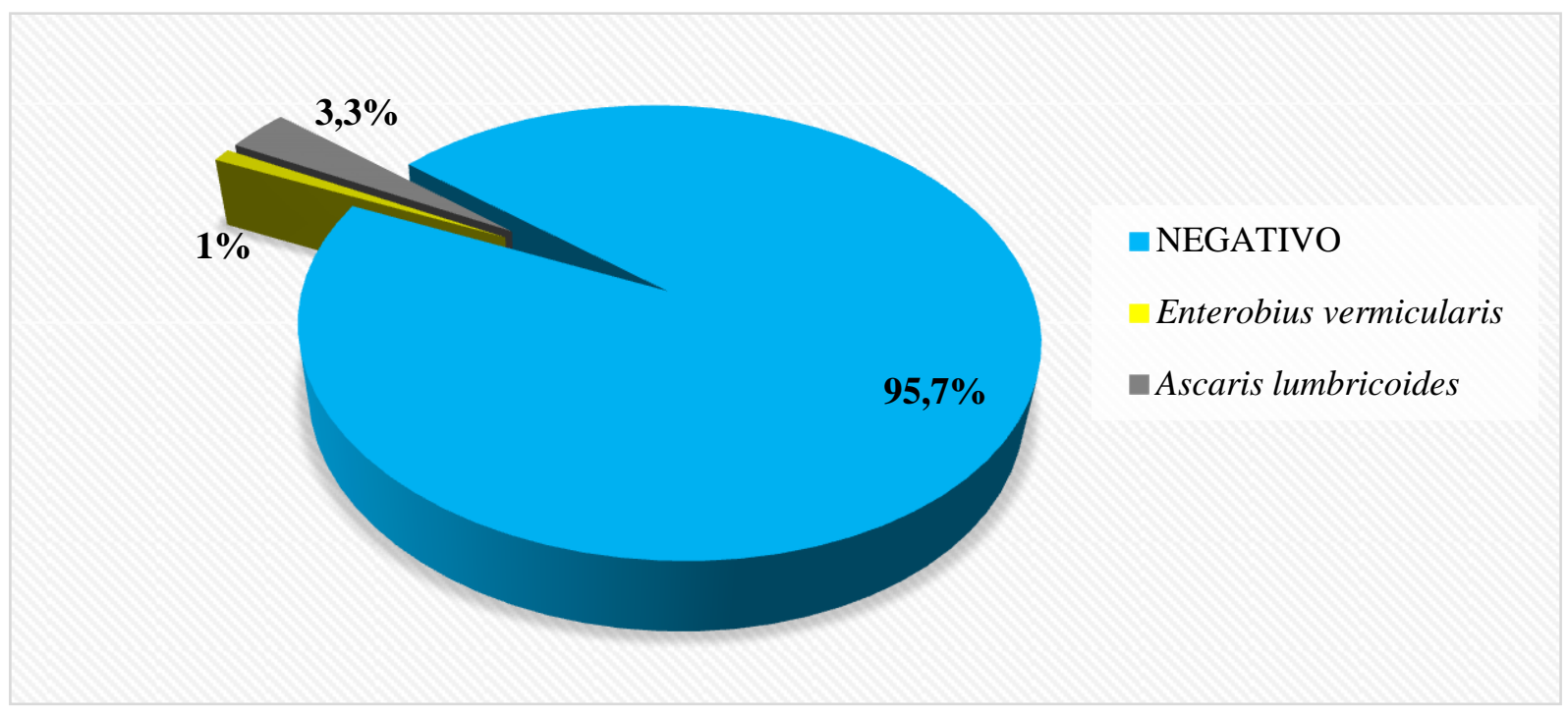

A maioria dos ovos observados estava estruturalmente intacta e suas características morfológicas podem ser visualizadas nas Figuras 2 e 3.
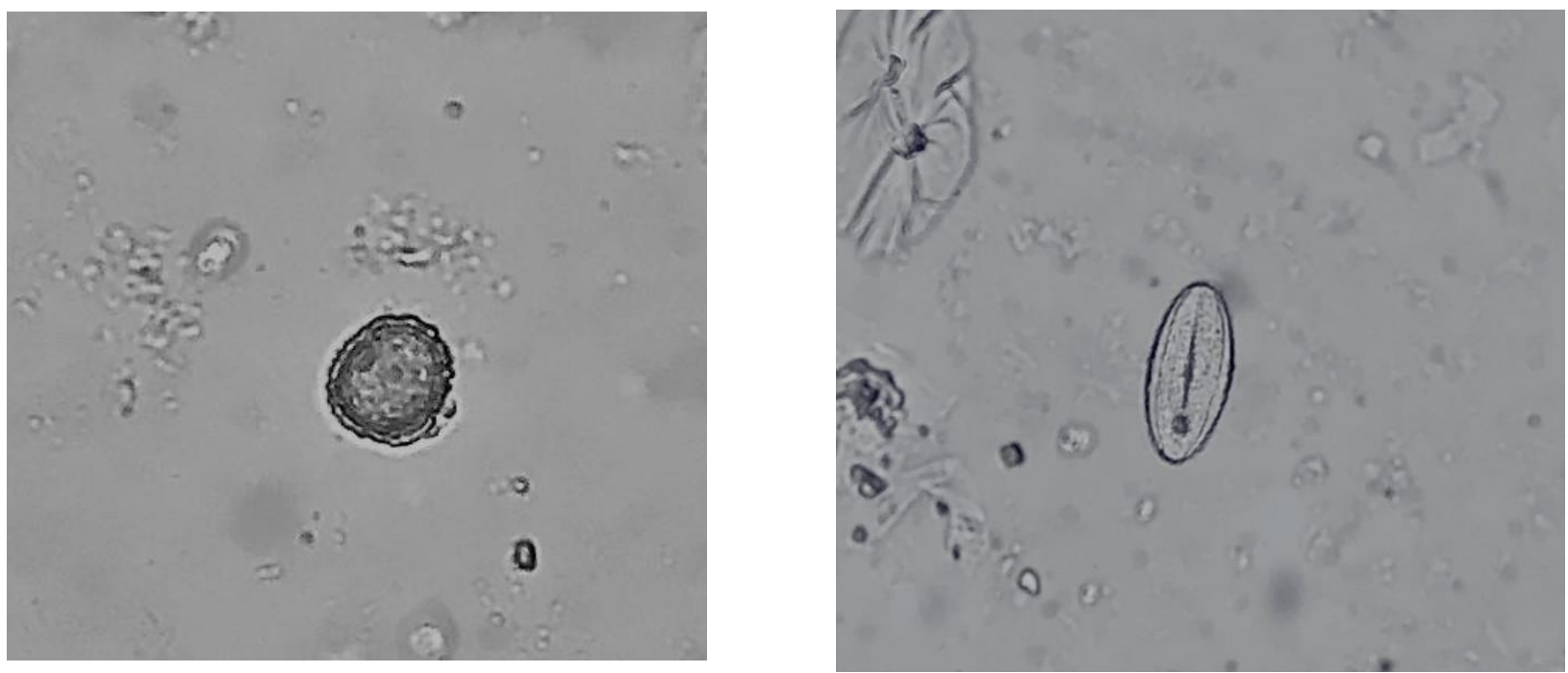
Figura 2. Ovo de A. lumbricoides encontrado na maçaneta interna do banheiro feminino na UBS F e observado no aumento de 400x.

Figura 3. Ovo de E. vermicularis encontrado na bancada de atendimento da UBS A e observado no aumento de 400x.

Embora os ovos de helmintos tenham grande resistência às condições desfavoráveis do ambiente, evidentemente, alguns ovos observados no estudo apresentaram alterações estruturais na membrana externa em decorrência da desidratação sofrida quando expostos ao meio ambiente por longos períodos (COELHO et al., 1999; LEONEL, 2014).

O estudo da presença de ovos de enteroparasitas, sobretudo helmintos, em locais de grande circulação de pessoas é uma investigação recorrente realizada por outro autores. Estes locais podem ser considerados uma importante fonte de contaminação, uma vez que os ovos são transmitidos pela via fecal-oral e facilmente disseminados pelas mãos e por objetos contaminados, reforçando o conceito de que o homem é o principal propagador dos ovos nestes locais. Já é documentada a ocorrência de amostras positivas para ovos de $E$. vermicularis em salas de espera e banheiros de UBS, ovos de A. lumbricoides e E. vermicularis em ônibus coletivos e em banheiros públicos, enteroparasitas em sanitários de Instituição de Ensino Superior e A. lumbricoides em instituição prisional (BORGES et al, 2009; MURTA e MASSARA, 2009; SILVA et al, 2013; VALADARES, FONSECA, WELTER, 2014; GIROTTO et al, 2016).

Uma vez ocorrendo à contaminação, as manifestações clínicas das helmintíases são diarreia e dores abdominais. Caracteristicamente, crianças parasitadas por A. lumbricoides podem apresentar atraso no crescimento e deficiência na cognição, além de sérios problemas de desnutrição. A obstrução intestinal em decorrência do enovelamento de parasitos na luz do intestino é a complicação mais frequente. Especificamente para o E. vermicularis, o prurido anal é a alteração mais intensa, mais incômoda e mais frequentemente relatada, causando irritabilidade e distúrbios do sono e, em alguns casos, pode provocar infecções secundárias. Nas infecções maciças o quadro pode evoluir para enterite catarral decorrente de ação mecânica e irritativa (MURTA e MASSARA 2009; ANDRADE et al, 2010; NEVES, 2011; SILVA et al., 2013).

Ainda que as UBS avaliadas neste estudo apresentem estrutura física em boas condições de funcionamento, foi possível evidenciar a importância da investigação proposta, do ponto de vista da saúde pública, uma vez que se observou a presença de ovos de helmintos $(A$. lumbricoides e E. vermicularis) em todas as seis UBS analisadas (Tabela 2 e 3). 
Tabela 2. Presença de ovos de A. lumbricoides encontrados em relação aos objetos e as Unidades Básicas de Saúde (UBS) no município de Ceres-GO

\begin{tabular}{|c|c|c|c|c|c|c|c|c|c|}
\hline \multirow[t]{2}{*}{ Locais de coleta } & & \multicolumn{6}{|c|}{$\begin{array}{c}\text { Unidades Básicas de Saúde } \\
\text { (UBS) }\end{array}$} & \multirow[t]{2}{*}{ Total } & \multirow[b]{2}{*}{ Contaminação } \\
\hline & & A & B & $\mathrm{C}$ & $\mathrm{D}$ & $\mathrm{E}$ & $\mathrm{F}$ & & \\
\hline Assento de cadeiras & & 0 & 0 & 0 & 0 & 0 & 0 & 0 & 0 \\
\hline Bancada de atendimento & & 0 & 0 & 1 & 0 & 0 & 1 & 2 & 28,6 \\
\hline \multirow{2}{*}{$\begin{array}{l}\text { Maçaneta interna } \\
\text { banheiros }\end{array}$} & feminino & 0 & 0 & 0 & 1 & 0 & 1 & \multirow{2}{*}{3} & \multirow{2}{*}{42,8} \\
\hline & masculino & 0 & 0 & 0 & 0 & 0 & 1 & & \\
\hline \multirow{2}{*}{$\begin{array}{c}\text { Maçaneta externas } \\
\text { banheiros }\end{array}$} & feminino & $\underline{0}$ & $\underline{0}$ & $\underline{0}$ & $\underline{0}$ & $\underline{1}$ & $\underline{0}$ & \multirow{2}{*}{2} & \multirow{2}{*}{28,6} \\
\hline & masculino & 0 & 0 & 0 & 0 & 1 & 0 & & \\
\hline Total & & 0 & 0 & 1 & 1 & 2 & 3 & 7 & \\
\hline \%Contaminação & & 0 & 0 & 14,3 & 14,3 & 28,6 & 42,8 & & 100 \\
\hline
\end{tabular}

Tabela 3. Presença de ovos de E. vermicularis encontrados em relação aos objetos e as Unidades Básicas de Saúde (UBS) no município de Ceres-GO

\begin{tabular}{|c|c|c|c|c|c|c|c|c|c|}
\hline \multirow[t]{2}{*}{ Locais de coleta } & & \multicolumn{6}{|c|}{$\begin{array}{l}\text { Unidades Básicas de Saúde } \\
\text { (UBS) }\end{array}$} & \multirow[t]{2}{*}{ Total } & \multirow{2}{*}{$\begin{array}{c}\% \\
\text { Contaminação }\end{array}$} \\
\hline & & A & $\mathrm{B}$ & $\mathrm{C}$ & $\mathrm{D}$ & $\mathrm{E}$ & $\mathrm{F}$ & & \\
\hline Assento de cadeiras & & 0 & 0 & 0 & 0 & 0 & 0 & 0 & 0 \\
\hline Bancada de atendimento & & 1 & 0 & 0 & 0 & 0 & 0 & 1 & 50 \\
\hline \multirow[b]{2}{*}{ Maçaneta interna banheiros } & feminino & 0 & 0 & 0 & 0 & 0 & 0 & \multirow[b]{2}{*}{1} & \multirow[b]{2}{*}{50} \\
\hline & $\begin{array}{l}\text { masculin } \\
\mathrm{o}\end{array}$ & 0 & 1 & 0 & 0 & 0 & 0 & & \\
\hline \multirow{2}{*}{$\begin{array}{l}\text { Maçaneta externas } \\
\text { banheiros }\end{array}$} & feminino & $\underline{0}$ & $\underline{0}$ & $\underline{0}$ & $\underline{0}$ & $\underline{0}$ & $\underline{0}$ & \multirow[b]{2}{*}{0} & \multirow[b]{2}{*}{0} \\
\hline & $\mathrm{o}^{\text {masculin }}$ & 0 & 0 & 0 & 0 & 0 & 0 & & \\
\hline Total & & 1 & 1 & 0 & 0 & 0 & 0 & 2 & \\
\hline \%Contaminação & & 50 & 50 & 0 & 0 & 0 & 0 & & 100 \\
\hline
\end{tabular}

A tabela 2 mostra a presença de ovos de A. lumbricoides nas as UBS C, D, E e F perfazendo um total de $n=7$ lâminas positivas. Destas, $n=3(42,8 \%)$ eram provenientes de maçanetas internas dos banheiros, sendo este o objeto com maior percentual de contaminação, seguido das maçanetas externas dos banheiros e bancada de atendimento, com $28,6 \%$ cada 
uma. Os resultados evidenciam ainda que, entre as lâminas positivas, o maior índice de contaminação foi encontrado na UBS F n=3 (42,8\%), seguido da UBS E $n=2(28,6 \%)$ e UBS C e D com $n=1(14,3 \%)$ de positividade cada uma.

A predominância de A. lumbricoides, nas maçanetas internas dos banheiros das UBS, analisadas $(42,8 \%)$ pode ser explicada pelo comportamento dos usuários. Acredita-se que a contaminação dos elementos sanitários possivelmente seja em decorrência do contato das mãos dos indivíduos com as fezes no momento da defecação. Portanto, a presença de fezes na superfície das estruturas dos banheiros, a higienização inadequada das mãos dos usuários dos sanitários da unidade, associada à precariedade na limpeza realizada na maçaneta, provavelmente justifica a contaminação destes locais por estruturas parasitárias. Confirmando, deste modo, a relevância desses objetos como possíveis transmissores de parasitos intestinais (SILVA et al., 2011; VALADARES, FONSECA, WELTER 2014; ALBANO et al., 2016).

A contaminação por ovos de A. lumbricoides nas bancadas de atendimento e nas maçanetas externas dos banheiros das UBS C, E e F correspondem a $n=2(28,6 \%)$ cada uma. Esses resultados revelam que os usuários da unidade estão em contato direto com estas estruturas durante o período de funcionamento da UBS, visto que são objetos de uso coletivo, podendo ser esta, uma condição determinante para ocorrer infecções. Estes objetos funcionam como disseminadores de enteroparasitas, uma vez que, pelas mãos contaminadas dos usuários, os micro-organismos podem propagar-se rapidamente no ambiente e contaminar outros indivíduos. Além disso, os ovos de A. lumbricoides exibem grande capacidade de resistência no ambiente, bem como excepcional capacidade de aderência às superfícies devido à sua membrana mamilonada (BASTOS, 2011; AGUIAR e LAMOUNIER, 2013; VALADARES, FONSECA, WELTER 2014; ALBANO et al., 2016).

$\mathrm{O}$ encontro do maior índice de contaminação na UBS F n=3 $(42,8 \%)$, provavelmente ocorre em virtude da localização periférica da unidade, uma vez que em área marginais, onde o nível socioeconômico é baixo e a educação sanitária é deficiente, verifica-se uma maior prevalência de enteroparasitoses (SILVA et al., 2013; VIANA et al., 2017). Embora este estudo não tenha realizado associações estatisticamente significativas entre a localização das UBS pesquisadas, com o índice de contaminação, existe uma estreita relação entre as variáveis sociais e higiênico-sanitárias com a presença de enteroparasitas nas unidades destes locais.

A presença de ovos de E. vermicularis na bancada de atendimento da UBS A e na maçaneta interna do banheiro da UBS B n=1 em cada uma (Tabela 3) pode sugerir a 
princípio, que os usuários da unidade apresentam hábitos higiênicos insatisfatórios, uma vez que já é bem documentado que o principal mecanismo de infecção da enterobiose é através das mãos contaminadas, inclusive debaixo das unhas. Normalmente, o indivíduo, mais comumente crianças, em decorrência do prurido anal, levam os ovos do ânus até a boca ou aos objetos do ambiente. Dessa forma, os ovos podem se disseminar no local, tornando-se infectantes em poucas horas e assim contaminar outros usuários da unidade (REY, 2010; NEVES, 2011).

Neste contexto, é importante ressaltar que, mesmo sendo baixo o índice de contaminação por parasitas nas seis UBS pesquisadas $n=9(4,3 \%)$, os usuários e funcionários das unidades encontram-se expostos a possíveis infecções parasitárias por um período significativo de dias nestes locais (SILVA et al., 2013).

Como as UBS são locais com grande circulação de pessoas, medidas preventivas devem ser estabelecidas a fim de se evitar possíveis contaminações. Dessa forma, é de extrema importância que sejam realizadas nas unidades a veiculação permanente de informações orientando os usuários a respeito dos princípios básicos de educação sanitária. Uma atitude simples e eficiente é afixar cartazes na unidade e distribuir panfletos com as orientações sobre higienização das mãos com água e sabão após o uso do banheiro e a utilização do álcool em gel para finalizar a desinfecção. No entanto, para que isso ocorra efetivamente, a UBS deve disponibilizar aos usuários dispensador com sabão, álcool e papel toalha nos sanitários das unidades (BATHKE et al., 2013; SILVA et al., 2013).

Outra forma interessante de inserir a adoção de medidas profiláticas no ambiente das UBS, é tornar os funcionários e profissionais daquela unidade agentes multiplicadores de informações a respeito das vias de contaminação e de prevenção de parasitoses. Com essa finalidade, pode-se instituir palestras abordando essa temática a fim de reciclar o conhecimento do pessoal. Dessa forma, a equipe, estando conscientizada e bem informada, poderá propor mudanças de hábitos a serem adotados no âmbito da unidade entre todos os usuários (FERREIRA e ANDRADE, 2005; BENCKE et al., 2006; MURTA e MASSARA, 2009).

No intuito de promover a saúde dos usuários das UBS é de fundamental importância que a adoção das práticas educativas propostas sejam efetivamente realizadas, uma vez que são decisivas para minimizar a contaminação e a dispersão dos parasitas no local. Sendo assim, é importante também ressaltar a limpeza e higienização adequadas dos objetos e superfícies da unidade. Uma vez concretizando as práticas educativas de prevenção nas UBS, 
o risco destes locais atuarem como disseminadores de parasitas e outras endemias, diminuem consideravelmente (BARBOZA e CARVALHO, 2017).

De fato, seria ideal a implementação do Protocolo de Limpeza e Desinfecção de Superfícies em Serviços de Saúde da Agência Nacional de Vigilância Sanitária nas UBS a fim de oferecer aos usuários dos serviços de saúde um local, com reduzida possibilidade de transmissão de infecções provenientes de fontes inanimadas (ANVISA, 2012).

\section{CONCLUSÃO}

Todas as UBS pesquisadas apresentaram positividade para presença de ovos de helmintos. No entanto, o índice de contaminação por parasitas $(4,3 \%)$ verificado nas seis UBS pesquisadas foi consideravelmente baixo.

Verificou-se a presença de ovos de A. lumbricoides nas as UBS C, D, E e F perfazendo um total de $n=7$ lâminas positivas. Destas, $n=3(42,8 \%)$ eram provenientes de maçanetas internas dos banheiros, sendo este o objeto com maior percentual de contaminação. Os resultados evidenciam ainda que, entre as lâminas positivas, o maior índice de contaminação foi encontrado na UBS F n=3 $(42,8 \%)$ possivelmente em virtude da localização periférica da unidade. A pesquisa evidenciou ainda a presença de ovos de E. vermicularis nas UBS A e B $(\mathrm{n}=2)$, distribuídas na bancada de atendimento e maçaneta interna do banheiro masculino, sugerindo a princípio, que os usuários apresentam hábitos higiênicos inadequados, uma vez que o principal mecanismo de infecção é através das mãos contaminadas, sobretudo, debaixo das unhas.

O baixo índice de contaminação por parasitas (4,3\%) verificado nas seis UBS pesquisadas neste estudo, sugere que a higienização do local e a desinfecção dos objetos e superfícies estão sendo realizadas de forma adequada, atendendo à proposta de manter o ambiente funcionando com mínima contaminação de parasitas circulantes.

Portanto, é essencial adotar medidas de prevenção nas UBS por meio da higienização correta das mãos, orientação através de cartazes educativos, além da implementação do Protocolo de Limpeza e Desinfecção de Superfícies em Serviços de Saúde da ANVISA. A associação destas ações certamente diminuirá significativamente o risco de infecção por parasitas no ambiente das UBS. 


\section{REFERÊNCIAS}

AGUIAR, N.S; LAMOUNIER, T.A.C. Pesquisa de cistos de protozoários e ovos de helmintos em cédulas de dinheiro na cidade do Gama-DF. Acta de Ciências e Saúde, v. 2, n. 2, p. 1-13, 2013. Disponível em: <

http://www2.1s.edu.br/actacs/index.php/ACTA/article/view/57> Acesso em: 26 nov. 2018

ALBANO, F.A.P. et al. Frequência de estruturas parasitárias em banheiros e salas aula de escolas públicas de Teresina, Piauí. Revista de Patologia Tropical, Goiânia, v. 45, n. 2, p. 192-202. abr./jun. 2016. Disponível em: 〈https://www.arca.fiocruz.br/handle/icict/18833> Acesso em: 11 out. 2018

ANDRADE, E.C. et al. Parasitoses intestinais: Uma revisão sobre seus aspectos sociais, epidemiológicos, clínicos e terapêuticos. Revista de APS, v. 13, n. 2, 2010. Disponível em: < https://aps.ufjf.emnuvens.com.br/aps/article/view/736> Acesso em: 18 nov. 2018

ANVISA. Segurança do paciente em serviços de saúde: limpeza e desinfecção de superfícies. 1.ed. Brasília, 2012. Disponível em:

$<$ https://www20.anvisa.gov.br/segurancadopaciente/index.php/publicacoes/item/segurancado-paciente-em-servicos-de-saude-limpeza-e-desinfeccao-de-superficies> Acesso em: 6 nov. 2018

BARBOZA, M.O; CARVALHO, A.S. Análise Parasitológica de contaminantes de origem fecal em banheiros Femininos de uma Instituição de Ensino Superior do interior da Bahia. Id on Line Revista de Psicologia, v. 10, n. 33, p. 237-248, 2017. Disponível em: < https://idonline.emnuvens.com.br/id/article/view/616/862>. Acesso em: 22 out. 2018

BASTOS, G.S.M. Desinfecção de efluente sanitário por radiação UV e Gama: efeitos na inativação de ovos de Ascaris spp. 2011. Disponível em: <http://hdl.handle.net/1843/BUOS8P2G7U> Acesso em: 8 nov. 2018

BATHKE, J. et al. Infraestrutura e adesão à higienização das mãos: desafios à segurança do paciente. Revista Gaúcha de Enfermagem, v. 34, n. 2, p. 78-85, 2013. Disponível em: <https://seer.ufrgs.br/RevistaGauchadeEnfermagem/article/view/29778> Acesso em: 25 nov. 2018

BENCKE, A. et al. Enteroparasitoses em escolares residentes na periferia de Porto Alegre, RS, Brasil. Rev. Patol. Trop, p. 31-36, 2006. Disponível em: <https://www.revistas.ufg.br/iptsp/article/view/1890/1805> Acesso em: 2 out. 2018 
BORGES, C.A.; COSTA-CRUZ, J. M.; PAULA, F. M. de. Intestinal parasites inside public restrooms and buses from the city of Uberlândia, Minas Gerais, Brazil. Revista do Instituto de Medicina Tropical de São Paulo, v. 51, n. 4, p. 223-225, 2009. Disponível em: $<$ http://www.scielo.br/scielo.php?pid=S0036-

$46652009000400009 \&$ script=sci_arttext\&tlng=es $>$. Acesso em: 24 out. 2018

COELHO, L.M.P.S et al. Ovos e larvas de helmintos nos sanitários de pré-escolas municipais de Sorocaba, SP e suas frequências nas fezes das crianças. Revista da Sociedade Brasileira de Medicina Tropical, v. 32, n. 6, p. 647-652, 1999. Disponível em: < https://s3.amazonaws.com/academia.edu.documents/36754712/0861.pdf?AWSAccessKeyId= AKIAIWOWYYGZ2Y53UL3A\&Expires $=1527993082 \&$ Signature $=0 \% 2 B R A L X Y o q E k G U 5$ fOnV2urA8HIHY\%3D\&response-content disposition=inline\%3B\%20filename\%3DOvos_e_larvas_de_helmintos_nos_sanitario.pdf $>$. Acesso em: 13 out. 2018

COELHO, L.M.P.S. et al. Detecção de formas transmissíveis de enteroparasitas na água e nas hortaliças consumidas em comunidades escolares de Sorocaba, São Paulo, Brasil. Revista da sociedade brasileira de medicina tropical, v. 34, n. 5, p. 479-482, 2001. Disponível em: < http://www.scielo.br/scielo.php?script=sci_arttext\&pid=S0037$86822001000500012 \& \operatorname{lng}=$ pt\&tlng=pt>. Acesso em: 21 out. 2018

FERREIRA, G.R.; ANDRADE, C.F.S. Alguns aspectos socioeconômicos relacionados a parasitoses intestinais e avaliação de uma intervenção educativa em escolares de Estiva Gerbi, SP. Revista da sociedade brasileira de medicina tropical, v. 38, n. 5, p. 402-405, 2005. Disponível em: < http://www.scielo.br/scielo.php?script=sci_arttext\&pid=S003786822005000500008>. Acesso em: 7 nov. 2018

GIROTTO, K.G. et al. Prevalência de parasitas intestinais nas dependências de uma instituição prisional. Revista Família, Ciclos de Vida e Saúde no Contexto Social, v. 4, n. 3, p. 194-200, 2016. Disponível em: < http://seer.uftm.edu.br/revistaeletronica/index.php/refacs/article/view/1781> Acesso em: 7 nov. 2018

GRAHAM, C.F.A device for the diagnosis of Enterobius infection. The American Journal of Tropical Medicine and Hygiene, v. 1, n. 1, p. 159-161, 1941. Disponível em: < https://www.ajtmh.org/content/journals/10.4269/ajtmh.1941.s1-21.159>. Acesso em: 21 out. 2018

LEONEL, L.P. Eficiência de um sistema simplificado de tratamento de efluentes na remoção de cistos de Giardia spp. e ovos de helmintos, 2014. Disponível em: <http://repositorio.unicamp.br/jspui/handle/REPOSIP/258420> Acesso em: 10 out. 2018 
MELO, A.C.F.L. et al. Aspectos epidemiológicos das enteroparasitoses em crianças de uma unidade pública de ensino de Parnaíba, Piauí. Journal of Health Sciences, v. 16, n. 3, 2015. Disponível em: <

http://www.pgsskroton.com.br/seer/index.php/JHealthSci/article/view/433/403>. Acesso em: 18 nov. 2018

MORALES, Y. R. Intervenção para Prevenção de Parasitose Intestinal em Unidade de Saúde Batinga, Arapiraca., Especialista (Especialização Estratégia Saúde da Família) Universidade Federal de Minas Gerais, Maceió, AL, 2016.

MURTA, F.L.; MASSARA, C.L. Presença de ovos de helmintos intestinais em ônibus de transporte público em Belo Horizonte- Minas Gerais, Brasil. Revista de Patologia Tropical, v. 38, n. 3, p. 207-212, 2009. Disponível em: <

https://www.revistas.ufg.br/iptsp/article/viewFile/7839/5641>. Acesso em: 22 out. 2018

NEVES, D.P. et al. Parasitologia humana. 12.ed. São Paulo: Atheneu, 2011.

REY, L. Bases da Parasitologia Médica. 3.ed. Rio de Janeiro: Guanabara Koogan, 2010.

REQUENA, I. et al. Enterobius vermicularis en pre-escolares de un área suburbana en San Félix, estado Bolívar, Venezuela. Investigación Clínica, v. 48, n. 3, p. 277-286, 2007. Disponível em: <http://200.74.222.178/index.php/investigacion/article/view/10768/10757>. Acesso em: 17 out. 2018

SCHOLTE, R.G.C. et al. Pesquisa de ovos de helmintos intestinais nos terminais aeroportuários Carlos Drummond de Andrade (Pampulha) - Belo Horizonte e Tancredo Neves-Confins-Minas Gerais. Revista de Patologia Tropical, v. 44, n. 3, p. 303-311, 2015. Disponível em: < https://www.revistas.ufg.br/iptsp/article/view/38016/19151>. Acesso em: 17 nov. 2018

SILVA, A.C.O.; BASTOS, O.M.P.; BRENER, B. Estudo da contaminação de elementos sanitários por estruturas enteroparasitárias em cinco pré-escolas públicas da cidade de Patrocínio-MG. Revista de Patologia Tropical, v. 40, n. 4, p. 315-322, 2011. Disponível em: <https://www.revistas.ufg.br/iptsp/article/view/16758/10204>. Acesso em: 3 nov. 2018

SILVA, A.T. et al. Ovos de Enterobius vermicularis em salas de espera e banheiros de unidades básicas de saúde (UBS) do município de nova Serrana-MG: contribuições para o controle. Revista de Patologia Tropical, v. 42, n. 4, 2013. Disponível em: < https://www.revistas.ufg.br/iptsp/article/view/27928/15776>. Acesso em: 2 out. 2018 
VALADARES, M.B.; FONSECA, H. M.; WELTER, A. Parasitos intestinais em sanitários públicos da cidade de Palmas-TO. Revista Cereus, v. 6, n. 1, p. 19-34, 2014. Disponível em: < http://ojs.unirg.edu.br/index.php/1/article/view/592/231> Acesso em: 27 out. 2018

VIANA, M.L. et al. Parasitoses intestinais e a inter-relação com os aspectos socioeconômicos de indivíduos residentes em um povoado rural (Rosápolis de Parnaíba-PI). Scientia Plena, v. 13, n. 8, 2017. Disponível em:

<https://scientiaplena.emnuvens.com.br/sp/article/view/3641/1785> Acesso em: 15 nov. 2018 